\title{
ARTICLE OPEN \\ Improving outcomes for people with COPD by developing networks of general practices: evaluation of a quality improvement project in east London
}

\author{
Sally Hull ${ }^{1}$, Rohini Mathur ${ }^{1}$, Simon Lloyd-Owen ${ }^{2}$, Thomas Round ${ }^{3}$ and John Robson ${ }^{1}$
}

BACKGROUND: Structured care for people with chronic obstructive pulmonary disease (COPD) can improve outcomes. Delivering care in a deprived ethnically diverse area can prove challenging.

AIMS: Evaluation of a system change to enhance COPD care delivery in a primary care setting between 2010 and 2013 using observational data.

METHODS: All 36 practices in one inner London primary care trust were grouped geographically into eight networks of 4-5 practices, each supported by a network manager, clerical staff and an educational budget. A multidisciplinary group, including a respiratory specialist and the community respiratory team, developed a 'care package' for COPD management, with financial incentives based on network achievements of clinical targets and supported case management and education. Monthly electronic dashboards enabled networks to track and improve performance.

RESULTS: The size of network COPD registers increased by $10 \%$ in the first year. Between 2010 and 2013 completed care plans increased from 53 to $86.5 \%$, pulmonary rehabilitation referrals rose from 45 to $70 \%$ and rates of flu immunisation from 81 to $83 \%$, exceeding London and England figures. Hospital admissions decreased in Tower Hamlets from a historic high base.

CONCLUSIONS: Investment of financial, organisational and educational resource into general practice networks was associated with clinically important improvements in COPD care in socially deprived, ethnically diverse communities. Key behaviour change included the following: collaborative working between practices driven by high-quality information to support performance review; shared financial incentives; and engagement between primary and secondary care clinicians.

npj Primary Care Respiratory Medicine (2014) 24, 14082; doi:10.1038/npjpcrm.2014.82; published online 16 October 2014

\section{INTRODUCTION}

Chronic obstructive pulmonary disease (COPD) is the fifth leading cause of death in the UK. It accounts for 30,000 deaths a year, 1.4 million general practitioner (GP) consultations, and one in eight emergency hospital admissions-and is therefore one of the most costly inpatient conditions treated by the NHS, accounting for nearly $10 \%$ of all bed days. ${ }^{1}$ The main cause of COPD is tobacco smoking, but it is also associated with occupational exposure, ${ }^{2}$ indoor air pollutants, ${ }^{3}$ alpha 1 antitrypsin deficiency ${ }^{4}$ and childhood respiratory infections. ${ }^{5,6}$ COPD is more prevalent in men, older people and in deprived and urban populations. ${ }^{7}$

Using data from the Quality and Outcomes Framework (QOF), the UK general practice pay for performance scheme, ${ }^{8}$ estimates the UK COPD prevalence to be $1.4 \%$, but epidemiological studies suggest that the prevalence is considerably higher. A cross-sectional study using Health Survey for England data estimated the UK COPD prevalence to be $3.7 \%$ in $2005 .^{9}$ Underdiagnosis appears to be more prevalent in urban areas, particularly in London. ${ }^{10}$

The majority of routine COPD management takes place in primary care, with the most cost-effective interventions being smoking cessation, flu immunisation and pulmonary rehabilitation. ${ }^{11}$

Structured care, particularly the early treatment of disease exacerbations, reduces morbidity and deterioration in the quality of life. ${ }^{12,13}$ In contrast to other major chronic disorders, such as diabetes, the evidence for promoting self-management, action plans or case management remains weak, except among selected subgroups of younger patients. ${ }^{14,15}$

Pulmonary rehabilitation is an effective intervention for COPD, with evidence of improvements in exercise capacity, healthrelated quality of life and dyspnoea. ${ }^{16}$ The effect size is considered to be greater than that of bronchodilator drugs. ${ }^{1,17}$ There is also evidence for reductions in length of hospital admissions. ${ }^{18}$ Rehabilitation should be considered at all stages of COPD when symptoms or disability is present (usually Medical Research Council dyspnoea grade 3 ).

The latest National Institute of Clinical Excellence COPD guidelines recommend a stepwise approach to COPD management including medication and a range of non-pharmacological interventions.

\section{The problem}

GPs in the east London borough of Tower Hamlets serve a population of 260,000 , of whom more than $50 \%$ are from ethnic minority groups, with $30 \%$ being south Asian. This population is one of the top three most socially deprived localities in England, and has adult male smoking rates of $24 \%$ compared with $20 \%$ for the whole of England. ${ }^{19}$ In 2012 a total of 3,466 people in the

\footnotetext{
${ }^{1}$ Centre for Primary Care and Public Health, Queen Mary, University of London, London, UK; ${ }^{2}$ Barts Health, NHS Trust, London, UK and ${ }^{3}$ Department of Public Health and Primary Care, King's College London, London, UK.

Correspondence: S Hull (s.a.hull@qmul.ac.uk)

Received 23 October 2013; revised 2 August 2014; accepted 12 August 2014
} 
borough had a GP-recorded diagnosis of COPD (crude prevalence $1.23 \%$, prevalence age standardised to the European standard population $2.2 \%)^{20}$

In 2008, Tower Hamlets was one of the top three localities in England for emergency COPD hospital admissions. ${ }^{21}$ At the time, there was little evidence of integrated care along the COPD pathway with no provision for hospital admission avoidance and poor provision of community-based pulmonary rehabilitation. The quality of primary care for COPD was suboptimal, with lower than expected rates of diagnosis and low take-up of regular care planning reviews and non-pharmacological interventions.

Recent evidence suggests that delivery of optimal, evidencebased interventions in ambulatory settings can prevent complications, reduce exacerbation rates, reduce time to recovery and reduce deterioration in the quality of life. ${ }^{15}$ In turn it is thought that these measures may prevent unnecessary hospital admission. ${ }^{1,22}$ It remains uncertain which model of ambulatory care translates into best outcomes, although there is evidence to suggest that health gain is greatest when the investment is in primary care settings. ${ }^{23}$

This project evaluates a locality-wide quality improvement project that involved all general practices in the area. Networks made up of four to five practices (population size 25-40,000) were tasked with collectively delivering an agreed care package for COPD. The aim of the package was to achieve measurable changes in clinically important indicators of COPD management between 2010 and 2013.

\section{Key measures for improvement}

A number of care package key performance indicators (KPIs) were chosen to assess the impact on COPD care in the locality. The focus of the care package was on COPD case finding, and ensuring that all patients, including the housebound, had a structured review and care plan annually or bi-annually depending on the severity of disease. The following indicators were financially incentivised at network level.

1. An increase in the number of COPD cases on network registers ( $10 \%$ in the first year).

2. An increase in the number of care plans completed in the previous 15 months, with a target of $80 \%$. Housebound patients were separately targeted.

3. Increased referrals to community-based pulmonary rehabilitation, with a target of $75 \%$ among those with an MRC dyspnoea scale of 3 or more. ${ }^{1}$

Annual influenza immunisation among people with a range of chronic conditions is already financially incentivised in the QOF. This indicator was included as a quality marker for the package, but did not receive further financial incentive, and no target was set for performance.

Smoking cessation, and referral for treatment, is similarly incentivised in the QOF, and hence was not included as a targeted KPI in the care package. However, the high prevalence of smoking in inner east London as a whole, and the high persistent smoking rates among people with COPD, is a continuing concern. Smoking prevalence and the record of stop smoking attempts were routinely monitored as part of the care package metrics.

We also tracked rates of emergency hospital admission for COPD among Tower Hamlets residents.

\section{MATERIALS AND METHODS}

In 2008 Tower Hamlets became a pilot site for a borough-wide integrated care programme. ${ }^{24}$ Tower Hamlets PCT chose to invest in the development of GP networks across the $36 \mathrm{GP}$ practices to improve the out-of-hospital care for a range of chronic diseases. ${ }^{25-27}$ Eight geographically clustered networks, each consisting of 4-5 neighbouring practices, were developed to deliver four chronic disease care packages of which COPD was one. The COPD care package, including all patients with spirometry values indicative of COPD, was phased in for all networks between April and June 2010.

The care package general practice activity and costings were developed by a group of local hospital and community clinicians supported by project management from a management consultancy firm. The content of the care package reflected National Institute of Clinical Excellence guidance. ${ }^{1}$ Clinical targets were set pragmatically, with the aim of extending the performance of clinical teams, but remaining achievable. The content of the care package focused on regular patient review and care planning for all, including the housebound. Using structured data entry templates for these reviews encouraged a systematic approach to monitoring the disease and co-morbidities such as depression and osteoporosis, reviewing medicine use, and encouraging the take-up of non-pharmacological interventions. Network coordinators provided a systematic approach to recall and management of non-attenders.

A further investment was in information technology (IT) required to provide real-time tracking of the KPIs for each of the care packages. As part of the set-up costs, each of the eight networks had funding for a network manager and recall coordinator to work across all care packages. All networks had training in organisational change and development. Network funding to deliver the COPD care package (approximately $£ 300,000$ across all networks per annum) was provided as $70 \%$ upfront running costs based on COPD register size and severity, and 30\% at the end of the year for achieving the care package targets collectively as a network (this was reduced proportionately according to the distance from the target for some networks). Each network had autonomy on the use and distribution of funds to achieve the KPI targets. Most developed a COPD team to provide local leadership and build practice engagement. Specialist support from the community respiratory team provided spirometry training to practices, community-based pulmonary rehabilitation and a hospital admission avoidance service. This involved a same-day home assessment and review service by respiratory nurse specialists. Provision of this additional expert home support (including prescription of nebulisers and medication as required) was designed to improve patient and GP confidence in managing more patients outside the hospital. The components of the network intervention are summarised in Figure 1.

The decision to fund networks rather than individual practices encouraged a process of peer scrutiny, and required the collective management of the financial resource. Network boards reviewed practice performance against targets, and the clinical leads worked with practice teams to support delivery and share best practice.

The introduction of a quarterly community COPD multidisciplinary team meeting (MDT), led by a respiratory consultant, provided educational support to all primary care clinicians, with discussion time for recent advances or guidelines, and complex cases (see Figure 2).

Network intervention summary

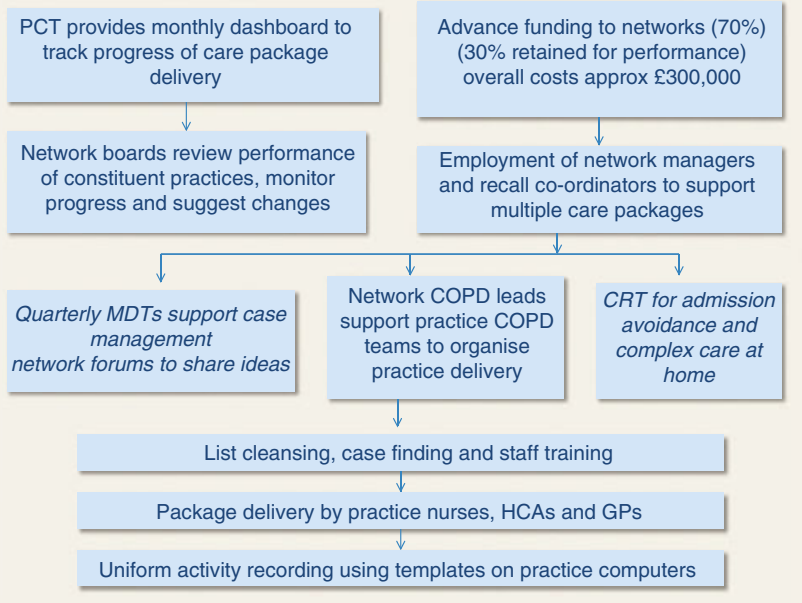

Figure 1. Flow chart to show summary of network intervention. CRT, community respiratory team; GP, general practitioner; HCA, healthcare assistant; MDT, multidisciplinary team; PCT, primary care trust. 
Information sources

We used EMIS Web (http://www.emis-online.com/emis-web) to collect demographics (age, sex, social deprivation and ethnicity) and routinely collected clinical COPD management data from all 36 general practices in Tower Hamlets, and similar data from two neighbouring primary care trusts (PCTs) to enable local comparisons. Hospital Episode Statistics (HES) data for COPD-related emergency hospital admissions for Tower Hamlets resident population were accessed from the Tower Hamlets commissioning support unit. These are collated for the whole population in financial years (April to March). Admission data for London and England up to 2010 were obtained from HES e-atlas (http://www.apho.org.uk/). All hospital admission rates were age standardised to the European standard population. Information on pulmonary rehabilitation and community respiratory team activity came from

\section{Multi disciplinary team meetings-the consultant's perspective}

Including MDTs as part of the COPD care package was crucial. We tend to work in silos and getting together with primary care and community colleagues to discuss COPD, and individual patients, has been enlightening. First, I think we all understand our own services better, and the challenges faced when looking after complicated patients: from pulmonary rehabilitation ('don't call it that to patients'), to oxygen assessments ('ear lobe blood gases') and the complexities and magic of the GP computer systems ( 'What does it say on EMIS?'). I did not realise how much of the work in primary care is done by the practice nurses and how important their hard work is. The probing of my knowledge during sessions has been good for me, I now make sure I have read up on every new guideline or study, because I am sure someone will ask about it. Certain issues have come up that we may not have thought about much before, such as fitness to fly assessments, lung transplantation and early palliative care involvement. The focus on the care package metrics (and payments), and the sharing of best practice to deal with them, has given the meetings a powerful direction. Most importantly, the patient discussions have been insightful. By thinking about one patient in detail, we worked out that frequent admissions were due to undiagnosed early dementia and her forgotten prednisolone. Concern that we had failed another patient because they were admitted was rightly challenged when we learned that they never let the community team into their house!

Finally, I have discovered parts of east London only previously viewed on an electronic map, and appreciate much better the communities and GP surgeries that we serve.

Figure 2. Multidisciplinary team meetings-the consultant's perspective. COPD, chronic obstructive pulmonary disease; MDT, multidisciplinary team. the Barts Health NHS Trust. Costs associated with network set-up and care package funding came from Tower Hamlets PCT.

The UK-wide Quality and Outcomes Framework was used for national comparisons of performance. ${ }^{8}$ All data were obtained from the Quality and Outcomes Framework online database, and all comparisons between localities were made without any reported exceptions. ${ }^{28}$ All QOF outcome data are crude counts of register size, and performance against a range of clinical targets collated at the end of the financial year for individual practices and for primary care organisations. Hence, the 2010 data refer to data collected on 31 March 2010 and reflect clinical activity during 2009-2010.

\section{Data analysis}

We used STATA version $10^{29}$ for all data analysis.

Comparative data for the eight networks were taken from the monthly dashboards, which are populated from EMIS Web searches. Small differences between data from the dashboard figures and those from the annual QOF returns occur because only COPD patients with recorded spirometry values are included in the care package. Values of each target for Tower Hamlets were compared annually with surrounding localities, the whole of London and England using the QOF online database.

\section{RESULTS}

Changes to the three care package KPIs that were financially incentivised are considered first.

COPD register growth (target 10\% for 2012 and 5\% for 2013) Improvement in the identification of people with COPD was a central aim for the network intervention. The observed prevalence of COPD is thought to be well below the predicted prevalence, with the gap between observed and expected prevalence estimated to be $2.1 \%$ for England. ${ }^{30}$ Tower Hamlets has a larger gap between observed and predicted prevalence at $2.4 \%$, reflecting the lower rate of diagnostic identification and recording.

The COPD register increase, summed across all networks, reached the care package target of $10 \%$ for 2012 and exceeded the 5\% target for 2013 (see Table 1). Overall, between 2010 and

Table 1. Achievement, by network, 2010-2013 for care package metrics

\begin{tabular}{|c|c|c|c|c|c|c|c|c|c|c|}
\hline & N1 & $N 2$ & N3 & N4 & N5 & N6 & $N 7$ & N8 & Tower Hamlets PCT & Care package target \\
\hline \multicolumn{11}{|c|}{ Network population size } \\
\hline July 2010 & 38,744 & 37,383 & 25,442 & 29,575 & 26,784 & 28,018 & 37,824 & 35,301 & 259,071 & \\
\hline March 2012 & 41,300 & 40,451 & 28,103 & 31,810 & 28,758 & 31,696 & 40,595 & 40,645 & 283,358 & \\
\hline March 2013 & 39,795 & 40,660 & 27,738 & 32,315 & 28,368 & 33,275 & 40,131 & 39,836 & 282,118 & \\
\hline \multicolumn{11}{|c|}{ COPD register size } \\
\hline July 2010 & 420 & 405 & 210 & 376 & 399 & 220 & 507 & 261 & 2,798 & Baseline \\
\hline March 2012 & 454 & 448 & 220 & 432 & 451 & 287 & 583 & 301 & $3,176^{a}$ & $10 \%$ Growth \\
\hline March 2013 & 479 & 481 & 239 & 457 & 487 & 310 & 617 & 321 & $3,391^{b}$ & 5\% Growth \\
\hline \multicolumn{11}{|c|}{$\%$ With annual review and self-management plan } \\
\hline July 2010 & 51.1 & 61 & 38.4 & 58.2 & 57 & 58.7 & 49.3 & 46 & 53.2 & Baseline \\
\hline March 2012 & 79.7 & 81 & 89.1 & 84.2 & 86 & 75.3 & 80.2 & 87.3 & 84.2 & $80 \%$ \\
\hline March 2013 & 77 & 83 & 92.5 & 89.3 & 87.5 & 90 & 88 & 88.9 & 86.5 & $80 \%$ \\
\hline \multicolumn{11}{|c|}{$\%$ With $M R C \geqslant 3$ referred to pulmonary rehabilitation } \\
\hline July 2010 & 47.6 & 41.1 & 33.3 & 52.6 & 49 & 52.3 & 41.8 & 45.4 & 45.6 & Baseline \\
\hline March 2012 & 60.8 & 61.3 & 40.6 & 58.8 & 57.4 & 89.6 & 55.7 & 56 & 60.1 & $75 \%$ \\
\hline March 2013 & 68.5 & 69.6 & 71.5 & 77.9 & 70.7 & 82.7 & 59 & 75.2 & 70.7 & $75 \%$ \\
\hline \multicolumn{11}{|c|}{$\%$ With annual flu immunisation } \\
\hline July 2010 & 85.2 & 84.9 & 84.8 & 79.5 & 80.2 & 82.7 & 86.2 & 85.4 & 83.6 & \\
\hline March 2012 & 89.1 & 86.4 & 87.3 & 81.3 & 84 & 82.6 & 81.8 & 85.7 & 84.4 & \\
\hline March 2013 & 86.2 & 84.4 & 84.5 & 84 & 83 & 84.2 & 84.1 & 83.2 & 84.2 & \\
\hline
\end{tabular}

N1-8 = eight general practitioner networks, each consisting of four or five geographically adjacent practices.

Abbreviations: COPD, chronic obstructive pulmonary disease; PCT, primary care trust.

${ }^{\mathrm{a}} 10 \%$ Increase in COPD register size.

${ }^{b} 7 \%$ Increase in COPD register size 


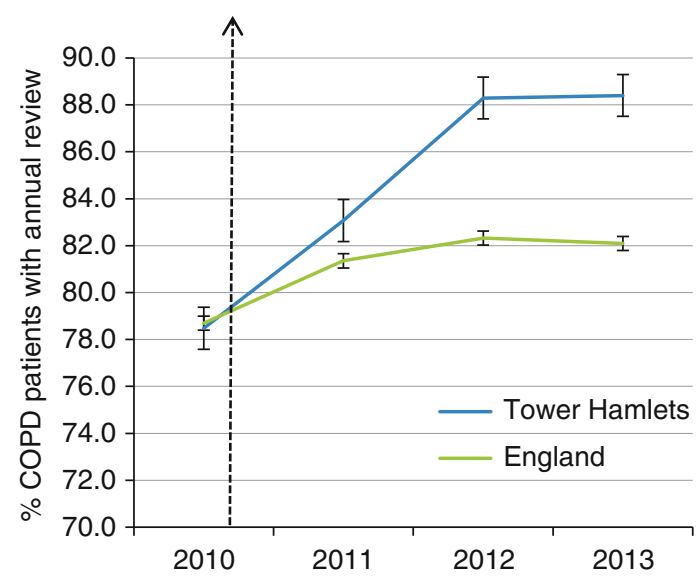

Figure 3. Chronic obstructive pulmonary disease (COPD) patients with a completed annual review. Tower Hamlets compared with England (95\% confidence intervals). Data are from Quality and Outcomes Framework with no exception reporting (http://www. gpcontract.co.uk). This indicator was introduced in 2010.

2013 , register size increased by $21 \%$. Networks used a variety of approaches to achieve this metric, including recalling smokers within target age groups ( $>35$ years) for spirometry, reviewing the diagnosis of asthma among persistent smokers, and including brief questionnaires for COPD in new patient registration checks.

\section{Care plans completed}

Annual review and care planning for people with COPD involves a collaborative consultation based on shared decision making and support for self-management, including referral to pulmonary rehabilitation and smoking cessation services. The proportion of people with a completed annual review rose from $53 \%$ at the start of the intervention to $86.5 \%$ in 2013 (see Table 1).

Figure 3 compares the annual QOF figures for Tower Hamlets with those for England for this metric. This shows sustained improvement between 2011 and 2013, the higher rates in Tower Hamlets being significantly different from England rates.

\section{Pulmonary rehabilitation referral}

The proportion of patients with an MRC dyspnoea scale value of 3 or more referred to pulmonary rehabilitation increased from $45 \%$ in 2010 to $70 \%$ across all the networks at the end of March 2013 (see Table 1). There is no national benchmark to use as a comparison for this metric.

The care package tracked other indicators including flu immunisation, smoking rates among people with COPD and hospital admissions.

Rates of annual flu immunisation for patients with COPD were already high in comparison with London and England in 2009, prior to the introduction of the practice networks. The rate of immunisation shows steady improvement, and for 2012 was significantly higher than the rate for England (see Table 1 and Figure 4). Sustaining this improved performance may be linked to the network infrastructure that supports patient recall and annual reviews. Although smoking cessation was a central component of the annual review, we were not able to show changes in smoking persistence among patients with COPD. At the start of the care package, 39\% were still smokers; in 2013 this value was $40.4 \%$.

\section{Hospital admissions}

Emergency COPD hospital admissions for all Tower Hamlets residents were tracked during the introduction of the care package. Historic high levels of emergency COPD admissions

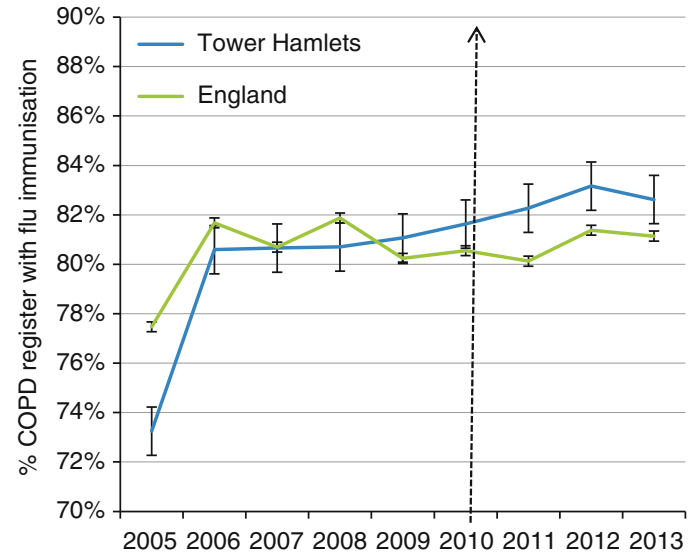

Figure 4. Rates of annual influenza immunisation for chronic obstructive pulmonary disease (COPD) patients. Tower Hamlets compared with England (95\% confidence intervals). Data are from Quality and Outcomes Framework with no exception reporting (http://www.gpcontract.co.uk).

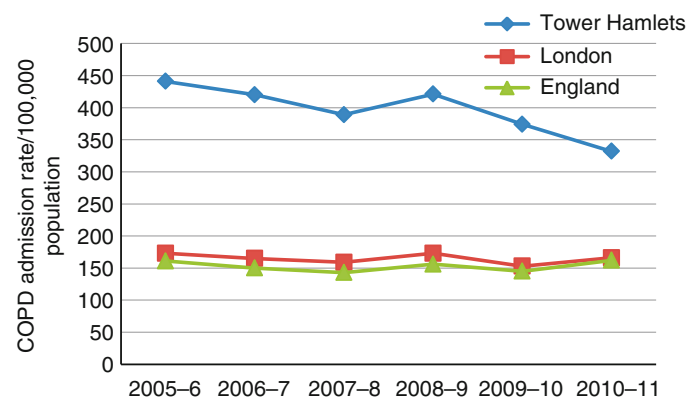

Figure 5. Chronic obstructive pulmonary disease (COPD) admissions, rates per 100,000 population, in Tower Hamlets 2007-2011 compared with London and England. Age standardised to the European Union population. Hospital admission data for London and England from e-HES atlas. Tower Hamlets data from e-HES and Tower Hamlets Commissioning Support Unit.

have fallen, although rates remain higher than the London average (see Figure 5). The introduction of an outreach team for admission avoidance may have contributed to further decline since 2011. The annual activity of this team for the year to March 2012 included 120 patients referred by GPs for admission avoidance. Of them, 24 required hospital admission within 28 days of referral.

\section{DISCUSSION}

\section{Main findings}

The network intervention introduced a combination of financial and organisational investment into geographical clusters of general practices. Behaviour change included IT-driven performance feedback, alongside educational facilitation and financial performance incentives at the network level.

Our results show that all eight networks achieved improvements in the identification of COPD cases within the practice population and for COPD care processes over the 3-year period. We also show that Tower Hamlets PCT achieved improvements in QOF indicators in comparison with England.

The targets for the care package were designed to challenge performance by the networks and to encourage network clinical leaders to work towards integrating essential community respiratory services into the care pathway. We report on hospital admissions, and note that the local rate for emergency COPD 
admission (which was among the highest in London) is reducing towards London and national rates. We speculate that improvements to preventive activity and exacerbation management may contribute to these results, alongside the work of admission avoidance by the community respiratory team. National admission rates for COPD show wide variations by primary care organisations (PCOs) and by practice, and are associated with COPD prevalence, social deprivation and higher population smoking rates. ${ }^{31}$ However, we are aware that at present there is no current UK evidence to link improvement in practice-based disease management with changes in COPD admission rates, and the observed results for Tower Hamlets may equally reflect changes to hospital practice or methods of coding hospital admissions.

Smoking prevalence remains high in Tower Hamlets, and there is a paucity of evidence on which stop smoking interventions work best with socially disadvantaged populations. ${ }^{32}$ Our analysis shows that on average $40 \%$ of COPD patients continue to smoke. Similar figures were found in Salford. ${ }^{33}$

Commissioning an adequate capacity of community-based pulmonary rehabilitation, in geographic locations spread throughout the borough, formed part of the integrated care pathway for COPD. However, even when there is good local provision, engagement of patients remains a challenge. Data from a London-wide collaboration on COPD ${ }^{11}$ suggest a $30 \%$ drop-out rate between referral and first attendance for assessment. Figures for Tower Hamlets showed high rates of referral into the service (70\% of patients) but we report a similar rate of $35 \%$ for attrition between referral and first attendance.

Findings in relation to previously published work

Integrated care programmes aim to improve clinical outcomes and patient experience by developing a range of organisational and clinical integration across primary, community and hospital settings. ${ }^{34-36}$ Programmes also aim to shift care from expensive acute hospitals to cheaper primary and community service settings for those conditions best managed out of hospital. ${ }^{24}$ The programme organisational structure can take a variety of forms, and there is little consensus on which structures best achieve, and sustain, the desired changes. ${ }^{37,38}$ Evidence from other out-of-hospital quality improvement schemes for COPD in the UK is scarce. Some London boroughs have introduced local pay for performance schemes, which have increased the prevalence of recognised COPD. ${ }^{39}$ Finding the 'missing millions ${ }^{\prime 40}$ is particularly important in London where the gap between observed and predicted prevalence is the widest. The Finnish 10-year national programme for COPD effected positive changes in the process of diagnosis and care, and a reduction in the number of hospital episodes was also noted. ${ }^{22}$

\section{Strengths and limitations of the study}

This evaluation benefits from the inclusion of all practices, and hence all patients with a diagnosis of COPD, in the study area. Engagement with the intervention, and performance as measured by the quantitative metrics, varied between networks, reflecting differences in the prior organisation and capacity of the constituent practices and differences between patients in the areas served. We found that a key factor for success was the engagement of clinicians, both in the planning, implementation and governance of the programme and in contributing to the educational support seen in the MDT meetings. However, the unique contribution in this initiative has been the financial investment in a practice network structure, alongside investment in an IT backbone to support the development of real-time information on clinical performance, which has high face validity for both clinicians and commissioners. Devolving resource and responsibility to groups of local providers enabled the practices to find collective local solutions to deal systematically with the complexities and fragmentation of existing care pathways. ${ }^{41}$

The decision to fund networks rather than individual practices encouraged a process of peer scrutiny and collective management of the financial resource. Network boards reviewed practice performance against targets and the clinical leads worked with practice teams to support delivery. The introduction of a quarterly community COPD MDT meeting, led by a respiratory consultant, provided ongoing education to all primary care clinicians, with discussion time set aside for analysis of key performance indicators, recent advances in treatment and individual discussion of difficult cases. The consultant also provided rapid access to advice by e-mail or telephone. These elements provided an alternative source of clinical support to reduce the need for outpatient referral.

The design of this quality improvement programme has important limitations. Practices were not randomised to the intervention, and other factors may have affected primary care management of COPD during the period of the intervention. Hence, uncertainty remains about the relationship between the intervention and the observed outcomes. Despite these limitations, routinely available data make essential contributions to the evaluation of system change programmes introduced pragmatically by commissioning organisations.

Implications for future research, policy and practice

For the future, there is a review of the care packages on a yearly basis. Targets are reviewed and stretched if necessary, or dropped in favour of others. We hope to develop greater input from patients to determine whether they consider the process of COPD care to have been enhanced as a result of the network care packages.

\section{Conclusions}

Improvements in COPD primary care in a socially deprived, ethnically diverse locality were observed over a 3-year period following financial and organisational investment into general practice networks.

\section{ACKNOWLEDGEMENTS}

This evaluation is based on the work of clinical staff in all the Tower Hamlets practice networks. We are grateful for the continuing support of PCT administrators and public health personnel. The CEG provided local data for this evaluation.

\section{CONTRIBUTIONS}

$\mathrm{SH}, \mathrm{JR}$ and TR had the original idea for the paper. RM provided the analysis and is responsible for the presentation of the data. SH, TR and SL-O wrote the first and final drafts. $\mathrm{SH}$ is the guarantor.

\section{COMPETING INTERESTS}

The authors declare no conflict of interest.

\section{FUNDING}

Tower Hamlets PCT.

\section{REFERENCES}

1 National Institute of Clinical Excellence. Management of Chronic Obstructive Pulmonary Disease in Adults in Primary and Secondary Care. NICE, London, UK, 2010.

2 Bakke PS, Baste V, Hanoa R, Gulsvik A. Prevalence of obstructive lung disease in a general population: relation to occupational title and exposure to some airborne agents. Thorax 1991; 46: 863-870.

3 Lopez AD, Mathers CD, Ezzati M, Jamison DT, Murray CJL. Measuring the global burden of disease and risk factors, 1990-2001. In: Lopez AD, Mathers CD, Ezzati M, 
Jamison DT, Murray CJL (eds). Global Burden of Disease and Risk Factors. World Bank: Washington, DC, USA, 2006

4 Stoller JK, Aboussouan LS. Alpha1-antitrypsin deficiency. Lancet 2005; 365 $2225-2236$

5 Galobardes B, McCarron P, Jeffreys M, Davey Smith G. Association between early life history of respiratory disease and morbidity and mortality in adulthood. Thorax 2008; 63: 423-429.

6 Barker DJ, Godfrey KM, Fall C, Osmond C, Winter PD, Shaheen SO. Relation of birth weight and childhood respiratory infection to adult lung function and death from chronic obstructive airways disease. BMJ 1991; 303: 671-675.

7 Mannino DM, Buist AS. Global burden of COPD: risk factors, prevalence, and future trends. Lancet 2007; 370: 765-773.

8 Doran T, Kontopantelis E, Valderas JM, Campbell S, Roland M, Salisbury C et al. Effect of financial incentives on incentivised and non-incentivised clinical activities: longitudinal analysis of data from the UK Quality and Outcomes Framework. BMJ 2011; 342: d3590.

9 Nacul LC, Soljak M, Meade T. Model for estimating the population prevalence of chronic obstructive pulmonary disease: cross sectional data from the Health Survey for England. Popul Health Metr 2007; 5: 8.

10 Nacul L, Soljak M, Samarasundera E, Hopkinson NS, Lacerda E, Indulkar T et al. COPD in England: a comparison of expected, model-based prevalence and observed prevalence from general practice data. J Public Health (Oxf) 2011; 33: 108-116.

11 London Respiratory Team. Annual Report. http://www.networks.nhs.uk/nhs-net works/respiratory-leads/documents/LON\%20Respiratory\%20Annual\%20Report\% 202011-12. 2012.

12 Kruis AL, Smidt N, Assendelft WJ, Gussekloo J, Boland MR, Rutten-van Molken M et al. Integrated disease management interventions for patients with chronic obstructive pulmonary disease. Cochrane Database Syst Rev 2013; 10: CD009437.

13 Wilkinson TM, Donaldson GC, Hurst JR, Seemungal TA, Wedzicha JA. Early therapy improves outcomes of exacerbations of chronic obstructive pulmonary disease. Am J Respir Crit Care Med 2004; 169: 1298-1303.

14 Bucknall CE, Miller G, Lloyd SM, Cleland J, McCluskey S, Cotton M et al. Glasgow supported self-management trial (GSuST) for patients with moderate to severe COPD: randomised controlled trial. BMJ 2012; 344: e1060.

15 Trappenburg JC, Monninkhof EM, Bourbeau J, Troosters T, Schrijvers AJ, Verheij TJ et al. Effect of an action plan with ongoing support by a case manager on exacerbation-related outcome in patients with COPD: a multicentre randomised controlled trial. Thorax 2011; 66: 977-984.

16 Lacasse Y, Goldstein R, Lasserson TJ, Martin S. Pulmonary rehabilitation for chronic obstructive pulmonary disease. Cochrane Database Syst Rev 2006, CD003793.

17 Ries AL, Bauldoff GS, Carlin BW, Casaburi R, Emery CF, Mahler DA et al. Pulmonary rehabilitation: joint ACCP/AACVPR evidence-based clinical practice guidelines. Chest 2007; 131(5 Suppl): 4S-42S.

18 Griffiths TL, Burr ML, Campbell IA, Lewis-Jenkins V, Mullins J, Shiels K et al. Results at 1 year of outpatient multidisciplinary pulmonary rehabilitation: a randomised controlled trial. Lancet 2000; 355: 362-368.

19 National Information Centre. Health and Social Care Information Centre. 2012 https://indicators.ic.nhs.uk/webview/. accessed on 13 August 2013.

20 Metadata: European Standard Population. http://www.wmpho.org.uk/localpro files/metadata.aspx?id = META_EUROSTD. 2013.

21 NHS Atlas of Variation. http://www.rightcare.nhs.uk/atlas/downloads/Respiratory AoV_2011.pdf. August 2013.

22 Kinnula V.L VT, Kontula E, Sovijarvi A et al. The ten year COPD programme in Finland: effects on quality of diagnosis, smoking, prevalence, hospital admissions and mortality. Prim Care Respir J 2011; 20: 178-183.
23 Starfield B, Shi L, Macinko J. Contribution of primary care to health systems and health. Milbank Q 2005; 83: 457-502.

24 Department of Health. Integrated care pilots: an introductory guide. www.dh.gov. uk/prod_consum_dh/groups/dh_digitalassets/documents/digitalasset/dh_106206. pdf.

25 Hull SA, Chowdhury T, Mathur R, Robson J. Improving outcomes for type 2 diabetic patients using general practice networks: a quality improvement project in east London. BMJ Qual Saf 2013; 23: 171-176.

26 Cockman $P$, Dawson $L$, Mathur R, Hull S. Improving MMR vaccination rates: herd immunity is a realistic goal. BMJ 2011; 343: d5703.

27 Robson J, Hull S, Mathur R, Boomla K. Improving cardiovascular disease using managed networks in general practice: an observational study in inner London. Br J Gen Pract 2014; 64: e268-e274.

28 Quality and Outcomes Framework online database. http://www.gpcontract.co.uk/ 15 November 2012

29 Statacorp. Stata Statistical Software: Release 10. Timberlake Consultants Ltd, London, UK,

30 COPD prevalence estimates Dec 2011 http://www.apho.org.uk/resource/item. aspx?RID = 111122

31 Calderon-Larranaga A, Carney L, Soljak M, Bottle A, Partridge M, Bell D et al. Association of population and primary healthcare factors with hospital admission rates for chronic obstructive pulmonary disease in England: national crosssectional study. Thorax 2011; 66: 191-196.

32 Michie S, Jochelson K, Markham WA, Bridle C. Low-Income Groups and Behaviour Change Interventions: A Review of Intervention Content and Effectiveness. The King's Fund: London, 2008.

33 Roberts JA, Maslin TK, Bakerly ND. Development of an integrated chronic obstructive pulmonary disease service model in an inner-city region in the UK initial findings and 12-month results. Prim Care Respir J 2010; 19: 390-397.

34 Department of Health. NHS London Strategic Plan 2008-2013. http://www.lon don.nhs.uk/webfiles/Corporate/NHSL_Strategic_Plan.pdf.

35 Ham C, Curry N. Integrated care summary: What is it? Does it work? What does it mean for the NHS?. The King's Fund: London, 2011.

36 Ham C, Dixon J, Chantler C. Clinically integrated systems: the future of NHS reform in England? BMJ 2011; 342: d905.

37 RAND Europe, Ernst and Young. National Evaluation of the Department of Health's Integrated Care Pilots. Department of Health: London, 2012.

38 Harris M, Greaves F, Patterson S, Jones J, Pappas Y, Majeed A et al. The North West London Integrated Care Pilot: innovative strategies to improve care coordination for older adults and people with diabetes. J Ambul Care Manage 2012; 35: 216-225

39 Falzon C, Elkin SL, Kelly JL, Lynch F, Blake ID, Hopkinson NS. Can financial incentives for improvements in healthcare quality enhance identification of COPD in primary care? Thorax 2011; 66: 630.

40 British Lung Foundation. Invisible Lives: Chronic obstructive pulmonary disease (COPD)_finding the missing millions. British Lung Foundation, London, UK, 2007 41 Shaw SE, Rosen R. Fragmentation: a wicked problem with an integrated solution? J Health Serv Res Policy 2013; 18: 61-64.

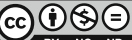

This work is licensed under a Creative Commons AttributionNonCommercial-NoDerivatives 4.0 International License. The images or other third party material in this article are included in the article's Creative Commons license, unless indicated otherwise in the credit line; if the material is not included under the Creative Commons license, users will need to obtain permission from the license holder to reproduce the material. To view a copy of this license, visit http:// creativecommons.org/licenses/by-nc-nd/4.0/ 